Journal of the British Association for Chinese Studies, Vol. 8 (2), July 2018 ISSN 2048-0601

(C) British Association for Chinese Studies

\title{
Working in No Man's Land: Between Sociology and Chinese Studies
}

\author{
Norman Stockman
}

University of Aberdeen

Having worked for my whole career in a department of sociology, and for the second half of that career primarily on aspects of Chinese society, I have continually reflected on the questions of what relationships there might be between sociology and Chinese studies, and how the study of Chinese society might relate to general theorising in sociology. I always thought of my own undergraduate course on Chinese society not just as an analysis of a specific society but as an exploration of the applicability (or otherwise) of sociological theories and concepts to a society other than those where sociological theory originally developed, but I discovered that this view was not widely accepted among my colleagues in sociology.

Similar questions have been posed by other China researchers in other contexts. Wang Mingming, one of the most prominent Chinese anthropologists, said in an interview conducted in 2010 that "people rarely consider the potential contribution of Chinese anthropology to world anthropology", and went on to suggest a simple explanation, that "China has been perceived as too special a case by sinological anthropologists" (Feuchtwang \& Rowlands, 2010: 912). In another interview (Wang, 2008), Wang sees it as his task to rectify this, and to incorporate the study of China into general anthropology. Much the same point was made by Frank Pieke in his inaugural lecture as Professor of Modern Chinese Studies at the University of Leiden (Pieke, 2012). Another example, in a quite different area, of the exclusion of China from general theorising can be found in Mark Elvin's comments on the influence of Joseph Needham's monumental Science and Civilisation in China. Elvin finds it "hard to comes to terms with ... the limited 
assimilation of Needham's work into the bloodstream of the history of science in general: that is, outside the half-occluded universe of East Asian specialists and a handful of experts sensitive to the decisive contributions of comparisons" (Elvin, 2008: xxv). He goes on to give some examples of mistakes that historians of science have made by failing to incorporate China into the general history of science.

The opposite argument, that it is mistaken, or premature, to incorporate the study of China into the mainstream of a discipline, can also be found. An example was Kevin O'Brien's keynote address to the Chinese Studies Association of Australia (CSAA) at the 2011 conference held at ANU (O'Brien, 2011). O'Brien bemoans the trend, as he sees it, for researchers on Chinese politics increasingly to be involved in general debates in political science which, because they are so specialised, fragment the community of China scholars who talk less and less to each other. In reply, Kelly Dombroski of Macquarie University explained in the CSAA Newsletter why members of her generation are deserting Chinese studies for the disciplines (Dombroski, 2011).

There is an extensive literature on the relationships between academic disciplines (of which sociology is one) and what has come to be known as "area studies" (of which Chinese studies is one example). Much of this literature starts from the premise that such relationships are fraught with difficulty, and much of it derives from the side of area studies practitioners, complaining about the stranglehold of disciplines on teaching and research in higher education and about the lack of attention paid in disciplinary work to the parts of the world investigated by area studies. In the introduction to one edited book on the topic, the editor criticises what he sees as the "parochialism" of the dominant disciplines, especially those in the social sciences, and claims that it is, or should be, the mission of area studies to "deparochialise" the disciplines (Szanton, 2004: 2). The social sciences and the humanities, especially in the United States, are seen to be immured in US- and Euro-centric visions of the world, which persist even when practitioners deign to extend their horizons to include other parts of the world.

But first, what counts as an "area"? The book just mentioned contains chapters on studies in the following areas: Latin American, Middle Eastern, 
African, Japanese, Soviet and Post-Soviet, Eastern European, Chinese, South Asian, and Southeast Asian (Szanton, 2004: v). Another such list can be extracted from the membership of the UK Council for Area Studies Associations (UKCASA) which, in addition to many of the areas already mentioned, also embraces American, Australian, Canadian, Caribbean, European, French, German, Iberian, Korean, and Low Countries Studies, for each of which there exists a British association. A couple of conclusions can be drawn from these lists: one is that areas refer to chunks of the globe of various sizes, from small countries to whole continents; the other is that for many of these chunks, but perhaps not all, one identifying feature is the existence of a shared language. In some cases, such as French, German or Iberian Studies, university language and literature departments have broadened out into the study of the history, politics, society, and so on, of the countries where those languages are spoken. In other cases, the belief has spread, for reasons I will touch on later, that larger areas of the globe have some cultural, political or economic significance, understanding of which requires a knowledge of the local language or languages which have hitherto been very much a minority interest among American or European academics; Middle Eastern Studies rooted in the study of Arabic would be such an example. Recently, the concept of "Language-based Area Studies" has become sufficiently prevalent to merit an acronym, "LBAS", and is much used in academic planning by the British higher education funding councils.

Area studies are many and various, and different area studies have different histories. Some can be traced back to earlier incarnations connected with European expansion around the globe, such as Chinese or African studies, or even further back to classical and biblical studies, as is the case with Middle East studies. The major British institutions in this stream of development include SOAS, the School of Oriental and African Studies at London University, founded as the School of Oriental Studies in 1916, and the Oriental Institute at Oxford University. Others are more recent, and stem from geopolitical concerns especially in the United States during and after the Second World War. This was when government agencies, backed by the major funding foundations (Ford, Rockefeller, Carnegie), encouraged the establishment of area studies centres in universities to train people in the linguistic, cultural and political knowledge needed for public policy in the Cold War. Since then, 
various area studies have risen or declined in importance according to the weight placed on them by governments. Most recently in Britain, collaboration between the research councils (ESRC and AHRC) and the funding councils in England and Scotland has promoted expansion in those language-based area studies thought to be of strategic and economic significance: Chinese (and other East Asian) Studies, Arabic and Middle East Studies, and Russian and East European Studies (AHRC, 2018).

Much of the literature on area studies is imbued with an assumption that relationships between area studies and the more conventional disciplines of university departments are fraught with difficulty. Proponents of area studies are often directly critical of disciplines such as economics, sociology and politics for paying too little attention to parts of the world other than America and Europe where these disciplines had their origins. Although they may well proclaim an aim of "de-parochialising" the disciplines, they also see themselves as providing more "holistic" accounts of their areas of the world, showing interconnections between the culture, society, economy, political system and so on, all of which can only be understood through in-depth knowledge of the language, literature and history of the area concerned, something which the separate disciplines are thought to be incapable of. And despite the presently fashionable moves to interdisciplinarity or transdisciplinarity, there are still many practitioners of disciplines who would reply, as the leading American sociologist of China Andrew Walder has done in his contribution to Szanton's book, that at least in the earlier stages of the development of Chinese studies, this area studies approach ran the risk of being "non-disciplinary" (Walder, 2004: 318).

\section{Fields of Tension}

I want to suggest that we can identify three fields of tension surrounding the relationships between disciplines and area studies, which I will exemplify by discussing the tension between sociology and Chinese studies. I call these: firstly, theoretical (or meta-theoretical or epistemological); secondly, political and geo-political; and thirdly, institutional or organisational. There are no hard and fast divisions between these sets of issues, but rather complex 
interconnections between them, but I want to try to summarise a few themes of each of them, and then go on to concentrate on the third, the institutional.

\section{Theoretical}

The first set of issues concern discussions on what kind of knowledge is aimed at by disciplines and by area studies and, as a corollary, what kind of research methods are appropriate for pursuing such knowledge. As mentioned earlier, some area studies claim to be producing holistic, all-inclusive accounts of the culture and society concerned, whereas disciplines carve out some particular aspect according to their disciplinary specialism. Some may connect this subject with long-standing and complex traditions of thought in the philosophy of science and epistemology. For example, one might go back to neo-Kantian debates in the later nineteenth century (which form the background to the work of Max Weber and others in sociology), and suggest that disciplines, especially in the social sciences, aim at nomothetic knowledge, seeking universal laws which govern social phenomena (rather as the natural sciences are supposed to do for natural phenomena), whereas area studies stress the uniqueness of the particular area, and therefore seek ideographic knowledge (Szanton, 2004: 20). The distinction and its application is, however, much disputed, both within disciplines such as sociology and between such disciplines and area studies. On the one hand, the very notion of uniqueness of cultures is sometimes hotly challenged even from within area studies: one could mention the splendidly vitriolic book on nihonjinron (discourse over Japaneseness) by Peter Dale, under the title The Myth of Japanese Uniqueness (Dale, 1986), or, in the Chinese studies context, the paper by Allen Chun with the title that should not be spoken in polite company, "Fuck Chineseness" (Chun, 1996). On the other hand, the de-parochialisation mission of area studies mentioned earlier can provoke attacks on social scientific generalisations of the form: "it's not like that in my area".

Another strand of dispute could be indicated by the common (but variously interpreted) anthropological distinction between "emic" and "etic" approaches, originally introduced by Kenneth Pike (Pike, 1967; Harris, 1976). "Emic" concepts refer to those in the mind, or culture, of the society being studied, while "etic" concepts are those used by the observer. While there is 
much discussion within anthropology and sociology about the place of these types of concepts in sociological and anthropological work, it is also sometimes argued that area studies quintessentially depends on understanding the culture and society in its own terms, hence the basic requirement that the area studies scholar learn the language or languages current in the area concerned. Opponents might well argue that this supports cultural relativism of a kind that would make social science impossible.

\section{Political and geo-political}

I have already pointed to the main point of political contention surrounding area studies: that the post-war thrust towards area studies came from primarily American interests in the cold war, and that area studies, so some think, continue to be bound to national interests defined by political elites. This is often countered with arguments and examples showing the independence of scholars from such political influences, or even their explicit opposition to officially defined interests, as in the case of the influential journal Bulletin of Concerned Asian Scholars and to some extent its successor, Critical Asian Studies. In the specific context of China, argument flows back and forth, and is joined by those who argue that China research in the social sciences is sometimes excessively shaped by agendas set within China. An example would be interpretation of the Cultural Revolution (CR), which shifted from political sympathy and interest in the period when Mao was alive, to critique which often paralleled the official reassessment of the CR after the trial of the Gang of Four. To cite just one example, Mobo Gao has published a series of papers and a book documenting this shift and criticising the overwhelming tone of rejection of Maoist discourse during the 1980s and early 1990s (Gao, 1994; 2008).

However, these discussions are also related to the processes of the globalisation of knowledge. As disciplines such as sociology which first emerged among scholars in Western Europe are exported to or imported by other parts of the world, a kind of dialectic is created between claims to universality of the discipline's theories and concepts, on the one hand, and accusations of the false universalisation of culturally specific theories and concepts, on the other. In the case of sociology, Martin Albrow, then editor of 
the journal International Sociology, argued at the time of the Madrid World Congress of Sociology in 1990 that the discipline was developing through five stages: the "universalism" of its founders Comte and Spencer, aiming to create a universal natural science of society; the "national sociologies" of the late nineteenth and early twentieth centuries, institutionalised in professional academic associations with their role in national systems of higher education and research; the "internationalisation" of the post-World War Two period, attempting to overcome the disaster of national rivalries by means of international associations bringing together national representatives, such as the various United Nations organisations and, in sociology, the International Sociological Association, founded in 1949; the "indigenisation" of the 1970s and 1980s, especially in the newly independent countries of the third world, where sociologists aimed to draw on their indigenous culture without importing inappropriate models of social science from the imperialist first world; and finally, the stage-in-the-making of "globalisation", which would be neither national nor international, but be created by networks of sociologists operating on a global scale (Albrow, 1990). In the case of China, as I have mentioned elsewhere (Stockman, 2000: 15), the phase of indigenisation can be seen in arguments in favour of the "sinification of sociology", which would draw on indigenous cultural concepts such as the social theory of Confucianism. Going beyond this, the phase of "globalisation", as Albrow conceived it, would require dialogue between different indigenised sociologies and discussion of possible cross-fertilisation. An example of such work might be the work of Xiaoying Qi, at the University of Western Sydney, on the possible fruitfulness of incorporating Chinese concepts such as "face" into general sociology (Qi, 2011). Once again, without going into the intricacies of these debates, we can see here another aspect of the intersection of theoretical and geo-political issues which infuse the tensions between disciplines and area studies in general, or between sociology and Chinese studies in particular.

\section{Institutional and organisational}

I turn now to the third set of factors which I call institutional and organisational. My aim here is to view these issues through the lens of the sociology of higher education, the sociological study of institutions of higher 
education and the people who work in them. Although this branch of sociological research is quite well developed, I have not yet found any systematic sociological research on the relationships between area studies and disciplines, so I can only outline my own observations to illustrate my ideas.

Burton Clark, a prominent American scholar who wrote prolifically on higher education organisations, argued that the primary membership group in universities is the discipline (Clark, 1983: 33-34). Academics are more likely to identify with their discipline than with, for example, the university in which they work. The discipline is the focus of their education and training and defines the parameters of their career path; their university is where they happen to be employed, often as a result of accidents of the academic labour market. Academics are more likely to move from one university to another preserving their disciplinary identity, rather than change disciplinary department within the same university. Within universities as organisations, disciplines are, at least in Anglo-Saxon types of universities, institutionalised as departments. So departments tend to have fairly strong boundaries between them, although this varies considerably from discipline to discipline.

Seen in this way, the problem of the relationship of disciplines to area studies can be recast as one of overlapping or competing principles for the organisational division of academic labour. In principle, universities could use either areas or disciplines as the basic element of organisational structure. As universities modernised in the nineteenth and twentieth centuries and ceased to be based on the renaissance curriculum of the trivium and the quadrivium, they tended to assume the discipline as the basic unit. Unusually, the University of Sussex, established in 1961, departed from this assumption. From its inception it was composed of Schools defined around area studies, such as the School of European Studies, the School of American Studies, and so on. If you worked as, for example, a sociologist in that university, you would be located in one or other of these Schools. A few years ago, however, the university was restructured along the lines of disciplinary departments, much to the disgust of some who had grown to appreciate the area studies schools.

In the case of Chinese studies, different universities have adopted different structures to accommodate and promote them. In some universities, such as Leeds, Sheffield or Edinburgh, Chinese studies are located primarily in a 
department rather like an extended modern language department. In others, Chinese studies are promoted by the establishment of interdisciplinary research centres, often with few of their own staff but serving as a focus for China specialists whose primary employment is in a disciplinary department, be it economic, history, and so on. A UK example might be the University of Manchester, with its China Institute together with the Chinese Studies section of the School of Modern Languages and Cultures. All of these different structures, however, reproduce for social science specialists on China a dilemma: where do I really belong? While evidence seems to suggest that disciplinary departments in the US have been more open to accommodating China specialists (for sociology, see Walder, 2004), in Britain, no such trend is immediately apparent. If anything, the reverse may be the case. A number of new and expanded Chinese studies centres, as well as expanded departments of East Asian Studies, have attracted many of the newly qualified as well as established China specialists in the social sciences, and relatively few sociology departments have made specific appointments of China researchers, Edinburgh being one notable exception. In one case, that of Nottingham, the university switched structures in 2016, moving staff in the hitherto expanding, and multidisciplinary, School of Contemporary Chinese Studies into disciplinary departments, two of whom went into sociology. Such vacillation points to the difficulty universities have in creating organisational forms that can embrace Chinese studies and sociology.

The problem is compounded if we turn to some other institutional aspects of academic life. Scholarly work in higher education is also promoted, encouraged, and protected by the formation of scholarly associations. While it may be logical and relatively inexpensive to be the member of both the relevant disciplinary and the area studies associations, attendance of conferences is a different matter. Does the sociologist specialising in China go to sociology conferences or to Chinese studies ones? The choice has consequences, as it may determine the networks that a scholar builds up, the potential audience for their research output, the job opportunities that may come his or her way.

A further, significant aspect of the dilemmas facing the sociologist working on Chinese society is the question of publication. Walder argues that, in the 
1970s, publication of social science articles on China centred on the China Quarterly, at least in part because research on China was not seen by the editors of social science journals as contributing to or related to debates in the social science disciplines; controversially, Walder claims that academics working on Chinese politics, economics or society were not sufficiently trained in the social science disciplines to be taken seriously by other practitioners of those disciplines. In recent years, there have been several changes which affect the possibility of publishing social science articles on China. On the one hand, there has been a great expansion in the number and range of Chinese studies journals, many of which are suitable for placing social science articles. On the other hand, it is supposedly the case that journals in social science disciplines have responded to the area studies mission to "de-parochialise" the disciplines by publishing more articles on other parts of the world. According to Walder, between 1978 and 2002 there had been modest increases in the number of articles about China in the sociology and politics journals, and a considerable increase in such articles in the one economics journal he examined. My own online searches resulted in rather different conclusions, as far as Britain is concerned. To take just the journal Sociology, the flagship journal of the British Sociological Association, as example, from its inception in 1967 up to 2013 there were just three articles relating specifically to China (one of which was authored by me). In the last four years, however, there has been a minor explosion of such articles, with eleven clearly related to aspects of Chinese society. A similar pattern can be found in the British Journal of Sociology. It seems that even sociologists working on China have not, until very recently, seen the major sociology journals as appropriate outlets for their research. One result of this is that such articles are not easily found by nonspecialist sociologists with an interest in China, although in the days of electronic access and sophisticated search engines, it has certainly become easier. But the fact remains that publication of sociological research on China in Chinese studies journals rather than sociology ones creates a barrier of sorts to the incorporation of China into general sociology.

The last set of institutional factors affecting relationships between sociology and Chinese studies that I want to touch on concerns government and administrative procedures for funding, auditing and evaluating academic activity. Funding has been a perennial issue for area studies, as for universities 
in general. I have already alluded to post-war moves to promote area studies, in which the milestones were the Scarbrough Commission on oriental languages and cultures of 1947, the Hailey Report of 1963, and the Parker Report of 1986. In fact, as far back as 1908, a Treasury Committee had bemoaned the weakness of provision in oriental studies in British universities, since when, every decade or so, the same soul-searching has been undergone. During the time of my involvement in Chinese studies, there were two further developments: first, toward the end of the 1990s, when pressure on the funding councils from BACS and the Foreign Office resulted in the provision of funding for new Master's programmes in Chinese studies at several universities, targeted at graduates in social sciences and history, and enabling them to gain sufficient language competence to go on to doctoral research on China; the second was the initiative at the beginning of the 2000s, already mentioned, to set up LBAS centres in East Asian, Arabic and Russian/East European/post-Soviet studies. But both of these developments were competing for funding with more established disciplines in the social sciences and humanities, and funding was provided on a pump-priming basis over five years, after which the universities concerned were expected to make the activities self-financing or fund them themselves. So, while complaints about the inadequacy of funding for postgraduate research are ubiquitous, tensions over funding between disciplines and area studies remain strong.

Finally, the position of Chinese studies, and area studies in general, in the processes of research assessment is worth a mention. When the RAE was set up in the 1980s, the basis for peer assessment of the quality of research was essentially disciplinary, with panels of assessors drawn from the various disciplines after consultation with stakeholders, notably including the professional or scholarly associations. For the RAE of 2008, research in sociology was to be submitted for assessment to the sociology panel 41, to be assessed by sociologists. Similarly, for the REF of 2014, sociology had its own sub-panel 23 of main panel C. In addition, panels were established to assess research in area studies. These changed somewhat from one RAE/REF to another but, for example, the 2008 RAE included a group $L$ of area studies panels, panel 47 on "American Studies and Anglophone Area Studies", panel 48 on "Middle Eastern and African Studies", panel 49 on "Asian Studies", and panel 50 on "European Studies" (RAE, 2008). By contrast, the 2014 REF 
reverted to a single panel for all Area Studies, namely sub-panel 27 of main panel $D(R E F, 2014)$. In the context of the present discussion, the question immediately arises of how sociological research on China was to be assessed. Was such research to be submitted to the sociology panel or to the Asian Studies or Area Studies panel? In practice, according to one informant on this matter (Tim Wright), submission of research was determined by the employing unit of the researcher concerned. If the researcher was employed in a sociology department, their publications were sent to the sociology panel; if they were employed in a department or a centre of East Asian studies, it was submitted to the Asian studies or Area Studies panel. There is no indication of whether the final assessment varied depending on which panel was doing the assessment and pieces are referred to other relevant panels or specialists wherever deemed necessary. But it is at least curious that this indeterminacy existed in the bureaucratic process. However, other countries with research assessment processes have used different structures. In the research assessment process in Australia, the ERA (Australian Research Council, 2018), there are no area studies panels, but only disciplinary ones. It might be argued that, where there are separate research assessment panels for area studies, as in the British RAE/REF, this constitutes another institutional obstacle to interaction between area studies and disciplines.

\section{Conclusion}

The argument I have been developing in this paper can be summarised as follows: together with a whole range of theoretical and political disputes and dilemmas, institutional and organisational factors within the processes of higher education and research operate to create and maintain barriers to fruitful interaction between sociology and Chinese studies, and quite possibly between disciplines and area studies more generally. In the terms of Burton Clark's sociology of higher education, these factors operate to maintain boundaries between sections of higher education institutions, defined as horizontally differentiated units making up the division of academic labour. Put another way, the more successful Chinese studies are in establishing their own departments, centres, associations, conferences, informal networks, funding streams, research assessment procedures, and so on, the more 
detached they become from disciplines in the social sciences and elsewhere, and quite possibly the less influence Chinese studies have within the disciplines, as a force for de-parochialisation or in any other way. The more Chinese studies own the study of China, the less incentive there is for sociologists and others to take account of China.

\section{References}

AHRC (2018), "Language-Based Area Studies", available at: https://ahrc.ukri.or $\mathrm{g} /$ research/fundedthemesandprogrammes/languagebasedareastudies/ (accessed 05.07.2018).

Australian Research Council (2018), "Excellence in Research for Australia", available at: http://www.arc.gov.au/excellence-research-australia (accessed 07.07.2018).

Chun, Allen (1996), "Fuck Chineseness: On the Ambiguities of Ethnicity as Culture as Identity", boundary 2 23(2): 111-138.

Clark, Burton (1983), The Higher Education System, Berkeley: University of California Press.

Dale, Peter N. (1986), The Myth of Japanese Uniqueness, London: Routledge.

Dombroski, Kelly (2011), "Writing in the Margins: Gen $Y$ and the (Im)possibilities of 'Understanding China'”, CSAA Newsletter 42 (August): 17-19.

Elvin, Mark (2008), "Vale Atque Ave”, xxiv-xliii, in K. G. Robinson (ed.), Joseph Needham, Science and Civilisation in China. Volume 7, Part II: General Conclusions and Reflections, Cambridge: Cambridge University Press.

Feuchtwang, Stephan and Michael Rowlands (2010), "Some Chinese Directions in Anthropology", Anthropological Quarterly 83(4): 896-924.

Gao, Mobo C. F. (1994), "Maoist Discourse and a Critique of the Present Assessments of the Cultural Revolution", Bulletin of Concerned Asian Scholars 26(3): 13-31.

Gao, Mobo (2008), The Battle for China's Past: Mao and the Cultural Revolution, London: Pluto Press.

Harris, Marvin (1976), "History and Significance of the Emic/Etic Distinction", Annual Review of Anthropology 5: 329-350. 
O'Brien, Kevin J. (2011), "Studying Chinese Politics in an Age of Specialization", Journal of Contemporary China 20(71): 535-541.

Pieke, Frank (2012), "Anthropology and the Chinese Century", inaugural lecture, University of Leiden, March 2, 2012, available at: https://openaccess.leid enuniv.nl/bitstream/handle/1887/19589/Oratie\%20Pieke_ENG.pdf?seque nce $=2$ (accessed 05.07.2018).

Pike, K. L. (1967), Language in Relation to a Unified Theory of the Structures of Human Behavior (2nd ed.), The Hague: Mouton.

Qi, Xiaoying (2011), "Face: A Chinese Concept in a Global Sociology", Journal of Sociology 47: 279-295.

RAE (2008), "Panels", available at: http://www.rae.ac.uk/panels/ (accessed 07.07.2018).

REF (2014), "Units of Assessment and Recruitment of Expert Panels", available at:

https://www.ref.ac.uk/2014/media/ref/content/pub/unitsofassessmen tandrecruitmentofexpertpanels/01_10.pdf (accessed 07.07.2018).

Stockman, Norman (2000), Understanding Chinese Society, Cambridge: Polity Press.

Szanton, David L. (2004), "Introduction: The Origin, Nature, and Challenges of Area Studies in the United States", 1-33, in David Szanton (ed.), The Politics of Knowledge: Area Studies and the Disciplines, Berkeley: University of California Press.

Walder, Andrew G. (2004), "The Transformation of Contemporary Chinese Studies, 1977-2002", 314-340, in David Szanton (ed.), The Politics of Knowledge: Area Studies and the Disciplines, Berkeley: University of California Press.

Wang, Mingming (2008), interview in series Film Interviews with Leading Thinkers, Alan Macfarlane (ed.), University of Cambridge, available at: https://www.sms.cam.ac.uk/media/1138095 (accessed 05.07.2018).

Norman Stockman is Emeritus Senior Lecturer in the Department of Sociology in the School of Social Science at the University of Aberdeen. 
15 Norman Stockman 